\title{
Factors associated with post-stroke depression and fatigue: lesion location and coping styles
}

\author{
Changjuan Wei ${ }^{1} \cdot$ Fang Zhang $^{1} \cdot$ Li Chen $^{1} \cdot$ Xiaofeng $\mathrm{Ma}^{1} \cdot$ Nan Zhang $^{1} \cdot$ \\ Junwei Hao ${ }^{1}$
}



Received: 28 July 2015/Revised: 24 October 2015/Accepted: 26 October 2015 /Published onl 14 Nov oer 2015

(C) The Author(s) 2015. This article is published with open access at Springerlink.com

\begin{abstract}
Post-stroke depression (PSD) and post-stroke fatigue (PSF) are frequent and persistent problems among stroke survivors. Therefore, awareness of signs and symptoms of PSD and PSF is important for their treatment and recovery from stroke. Additionally, since sudden serious illness can result in disequilibrium, early institution
\end{abstract} of a coping process is essential to restoring stability. $T$ brain damage of stroke leaves patients with unique physica. and mental dysfunctions for which coping mayb a key resource while rebuilding lives. We evaluated consecutive patients with acute ischemic stroke f or post-s 1\% emotional disorders at admission and $3 \mathrm{~m} m \mathrm{nc}$ later. PSD was evaluated by using the Beck Deprese' on Inve. $z y$, and PSF was scored with the Fatigue Seve ity Scale. The Social Support Rating Scale and Medical oping Ilodes Questionnaire were also used as measuren. Locations of lesions were based on $M$ Those scans revealed infarcts located in the basal gargia. corona radiate and internal capsule and cons uted the independent factors associated with PSr after stroke occurrence. Conversely, PSD was related to lesion location. Acceptance-re $1 \mathrm{~g}_{1}$ ion related to PSD and PSF both at admission and 3 mo $\%$ after stroke. Avoidance was the independ nt factor most closely related to PSD, whereas confronta was the independent factor best related to PSF 3 mo 3 after stroke onset.

Junwei Hao

hjw@tijmu.edu.cn

1 Department of Neurology and Tianjin Neurological Institute, Tianjin Medical University General Hospital,

Tianjin 300052, China
Keyword, Pos ance depression - Post-stroke fatigue . Coping styles esion location

\section{Introduction}

h year, of the approximately 15 million human stroke vi tims worldwide, at least five million die, and one-third emain disabled [1]. Overwhelming feelings of fatigue, that is, tiredness and lack of energy, is the chief complaint in more than half of the 10 million survivors [2]. Fatigue as a common post-stroke emotional disturbance always impairs patients' ability to regain lost functions [3] and leads to negative long-term outcomes. Similarly, post-stroke depression (PSD) mainly manifested as sadness, reduction of interest and pleasure, and multiple psychological and vegetative symptoms [4] afflicts $20-65 \%$ of these patients, depending on the population studied, the assessment measures, and the definition of depression applied [5]. As the most common psychological sequel of stroke, patients who had PSD experienced the least benefit from rehabilitation, the poorest quality of life and a substantially increased risk of suicide [6].

Several cross-sectional papers have linked fatigue with depression after stroke [7]. In a Swedish study, $49 \%$ of patients with fatigue 1 year after stroke were diagnosed with depression compared with $39 \%$ in the total sample [8]. Similarly, in a Korean study, $34 \%$ of patients diagnosed as depressed were among those with fatigue approximately 15 months after stroke [7]. Fatigue was considered an essential component of PSD [9], and depression-related symptoms such as insomnia or appetite loss resulted in fatigue [10]. In contrast, PSF accompanying PSD is often relieved when the depression is adequately treated [11]. An association between these two syndromes 
at a particular time point does not necessarily mean that one causes the other or exclude the possibility that a third factor causes both. Nevertheless, among all these attempts to make sense of PSD and PSF, identifying predictors and early signs is crucial for taking preventive measures, promoting early diagnosis, implementing early and adequate treatment, and improving quality of life, both for patients with stroke and for their caregivers.

Some studies invoke more physiologic than behavioral causes for PSD and PSF by suggesting that the extent of stroke-induced functional residual impairment is the major risk factor. Others suggest a possible biological relationship between the occurrence of emotional disturbances and structural brain damage [5]. However, the effect of lesion location has remained the most controversial purported cause of PSD and PSF. With, social support and coping styles also prominent considerations. Coping refers to the person's cognitive and behavioral efforts to manage (reduce, minimize, master, or tolerate) the internal and external demands of his/her environment that seem too taxing or exceed personal resources [12]. Moos and Tsu [13] proposed that sudden serious illness often results in disequilibrium, which triggers adaptive processes to restore equilibrium. The coping process, initiated to restore equilibrium (adaptation), includes cognitive appraisal of $t^{\prime}$ e illness, identification of adaptive tasks and coping skilıs Contextual factors (background, patient illness and socialenvironmental variables) shape these coping Emotional disturbance and physical health a e desig as adaptation outcomes. Since stroke is c ns red a special physical illness with neurologica dysfun and brain damage, coping may be th key psychological resource involved in rebuilding $t$ lives of patients. Studies assessing coping strategies in ats after stroke have produced inconsistent resu 11 In this context, we evaluated PSD and PSF at differ nt stages after cerebral infarction and attempted. corre' $x$ te patients' symptoms with lesion location, in a s and other variables. The goal of this research is nrovide new insight into the rehabilitation na anagement of stroke.

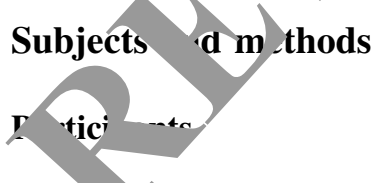

This dyscriptive, cohort study was conducted with stroke patients upon admission and at 3 months afterward. Our study was approved by the ethics committees of Tianjin Medical University General Hospital. All participants provided written informed consent. We evaluated 989 consecutive patients who were admitted to Tianjin Medical University General Hospital (Tianjin, China) with a diagnosis of acute stroke, between Jan 2012 and Jun 2014. The diagnosis was confirmed based on CT or MRI findings within 7 days after stroke onset. Exclusion criteria applied to patients with hemorrhagic stroke $(n=83)$; those with unusual causes such as dissection, venous infarction, or moyamoya disease $(n=77)$; those with transient ischemic attack without progression to stroke $(n=120)$; those with communication problems (decreased con io nes, confusion, aphasia, dementia, or dysarthria) sev erough to preclude a reliable interview $(n=142)$; and hose with very severe neurologic or medical nditions (such as metastatic cancer) $(n=54)$. We also cluded patients who scored $\leq 23$ on the $M$ $(n=31)$, patients diac ased ith depression or other psychiatric illnesses or th ted with selective serotonin reuptake inhibitor efore th onset of stroke $(n=16)$, patients who lived a e (because no information was available fro latives $(n=9)$, patients who did not undergo a $\mathrm{mp}$ follow-up $(n=37)$, and patients who did not sign . informed consent $(n=52)$. Finally, 368 patien were en slled into the study.

Before in. project began officially, all interviewers/ raters completed and passed a consistency-training examination. 'Two researchers (L.C. and F. Z.) recorded all ical and socio-demographic information. The neuro sychological evaluations were recorded by one of the athors (C. W.) and supervised by a psychiatrist (L. L.). An experienced stroke neurologist (N. Z.) documented patients' neurologic findings during the 3-month follow-up, and one of the authors with experience in neuroimaging ( $\mathrm{F}$. Z.) analyzed MRI and Fazeka's scale scores. Questions arising during subsequent interviews were brought to a research team meeting for group consensus on the appropriate answer.

\section{Testing instruments}

Depression was assessed with the Beck Depression Inventory (BDI) [15], which was self-recorded. Fatigue was measured on the fatigue severity scale $[16,17]$. To calculate cognitive functioning we applied the Mini-Mental State Examination (MMSE) [18], a measure of global cognitive decline that encompasses basic cognitive domains. The Social Support Rating Scale (SSRS) [19] was adopted to evaluate social support, which consisted of three dimensions: objective support, subjective support and the degree of social utilization. Coping styles were measured with the Medical Coping Modes Questionnaire (MCMQ) [20, 21], which is a 19-item instrument that addresses three forms of coping: confrontation, avoidance and acceptanceresignation.

MRI studies were performed on a 3.0T clinical scanner (HDx, General Electric, USA) with an 8-channel phase- 
array coil. Locations of lesions based on MRI were characterized as anterior cortical when identified in the anterior cerebral artery territory, the frontal and parietal areas of the middle cerebral artery, or predominantly in the temporal lobe of the middle cerebral artery territory. Posterior cortical referred to the lesions at the following occipital area or medial temporal area of the posterior cerebral artery territory; internal capsule/corona radiata/basal ganglia of the lenticulostriate artery territory; thalamus; pons, including pure midbrain lesions; medulla; and cerebellum [19]. White matter intensity (leukoaraiosis) derived from fluid-attenuated inversion recovery (FLAIR) imaging was graded from 0 to 3 on Fazeka's scale of deep white matter changes, with scores of 2 and 3 indicating significant leukoaraiosis [20].

\section{Procedure}

Each first interview was completed at approximately 14 days after the onset of stroke to ensure that the patients were stable. We tried our best to avoid conducting the interviews under conditions of acute neurologic progression or any other condition that could affect the emotions of patients or assessments made by our team. To ensure that each evaluation was reliable, patients were asked 0 take the interview accompanied by the caregiver wholive with $\mathrm{him} / \mathrm{her}$. The caregiver was present to velfy the information and to assist the patient, but could nor. part in the assessment. Neurologic and psychol gical a ments (including BDI, FSS, SSRS, MCMC, I ka's seale and symptom observation) were com eted by assigned specifically for that purpose MMSE was used for cognition screening, excluding de entia. The second patient interview was performed 3 mo after the onset of stroke. Neurologic and psyc ical assessments were completed by the same doctors who conducted the first interview.

\section{Diagnostic critera}

PSD was dingnosed patients with a BDI score $>13$ or those wh met the Diagnostic and Statistical Manual of Mental D ders DSM-IV) [22, 23]. The presence of PSF is $\mathrm{d}$ as FSS score of 4.0 or more, because fewer t. 5 f healthy controls rate their fatigue at that level. How er, 60-90\% of patients with medical disorders experie, ice fatigue at or above that score [3].

\section{Statistical analyses}

Ages, years of education, MCMQ and SSRS scores were compared using Mann-Whitney $U$ tests, because they were not normally distributed. Variables of frequency were compared using Chi-square tests. Fisher's exact probability test was used in tests of dichotomous variables when small numbers were involved. Multiple logistic regression analysis was used to explore relationships among PSF/PSD variables. The level of significance was set at $P<0.05$. All data were analyzed by SPSS version 19.0 (IBM Corp., Armonk, NY).

\section{Results}

\section{Prevalence of PSD and PSF}

A total of 368 particin ts an olled within 14 days after the onset of rok nd completed their second interview at 3 mor after thy stroke. PSD was diagnosed in $19.3 \%$ of the pat ts at admission and in $23.6 \%$ at 3 months. Of 71 pat ents who developed PSD during the acute of o conce, 23 recovered but 48 still had PSD after 3 month. ' $n$ comparison, 39 patients without PSD at admis on had dy-veloped PSD at 3 months. PSF was present in $23 . \mathrm{r}$. of the patients at admission and in $29.6 \%$ at 3 month. Of the 86 patients who developed PSF during the acute stage of stroke, 28 recovered and 58 still had PSF . 3 months, whereas 51 patients without PSF at admission de reloped PSF at 3 months. Further, $75.6 \%(65 / 86)$ of the atients who had PSF at admission presented with PSD 3 months after stroke. More than half $(38 / 71,53.5 \%)$ of the patients who had PSD at admission presented with PSF 3 months after stroke. In addition, $10.9 \%(40 / 368)$ and $12.2 \%(45 / 368)$ of the patients had PSD accompanied by PSF at admission and 3 months later, respectively.

\section{Factors related to PSD and PSF}

Both motor and sensory dysfunction at admission $(P<0.01)$ compared with only motor or only sensory dysfunction was related to PSD at admission. Patients who prefer acceptance-resignation (MCMQ; $P<0.01$ ) were prone to PSD at admission. Three months later, none of the above risk factors for PSD changed significantly. Moreover, the patients who manifested a lower degree of social utilization (SSRS; $P<0.05$ ) and chose avoidance coping styles (MCMQ; $P<0.01$ ) were more prone to PSD. We also found that the patients who had only sensory dysfunction at admission $(P<0.05)$ were not susceptible to PSD (Table 1).

Patients with both motor and sensory dysfunction $(P<0.01)$ were more susceptible to PSF at admission compared to individuals with motor or only sensory dysfunction $(P<0.01)$. Moreover, acceptance-resignation (MCMQ; $P<0.01)$ styles, low objective support (SSRS; $P<0.05$ ) and degree of social utilization (SSRS; 
Table 1 Factors associated with PSD at admission and 3 months later

\begin{tabular}{|c|c|c|c|c|}
\hline \multirow[t]{2}{*}{ Variable } & \multicolumn{2}{|l|}{ Admission } & \multicolumn{2}{|c|}{3 months after stroke } \\
\hline & Present $(n=71)$ & Absent $(n=297)$ & Present $(n=87)$ & Absent $(n=281)$ \\
\hline Age $(y)$, mean \pm SD & $61.3 \pm 9.4$ & $61.6 \pm 9.8$ & $62.0 \pm 9.7$ & $60.0 \pm 9.6$ \\
\hline Female, $n(\%)$ & $21(29.6)$ & $86(29.0)$ & $29(33.3)$ & $78(27.8)$ \\
\hline Education $(\mathrm{y})$, mean $\pm \mathrm{SD}$ & $10.7 \pm 3.5$ & $10.8 \pm 3.4$ & $11.0 \pm 3.7$ & \\
\hline Previous stroke, $n(\%)$ & $33(46.5)$ & $147(49.5)$ & $38(43.7)$ & \\
\hline \multicolumn{5}{|l|}{ Weekly working time, $n(\%)$} \\
\hline $0 \mathrm{~h}$ & $52(73.2)$ & $164(55.2)$ & $56(64.4)$ & (56.9) \\
\hline $1-20 \mathrm{~h}$ & $1(1.4)$ & $10(3.4)$ & $1(1.1)$ & $35.6)$ \\
\hline $21-30 \mathrm{~h}$ & $2(2.8)$ & $20(6.7)$ & $2(2.3)$ & $20(7.1)$ \\
\hline $31-40 \mathrm{~h}$ & $7(9.9)$ & $64(21.5)$ & $(127.2$ & $56(19.9)$ \\
\hline $41-50 \mathrm{~h}$ & $5(7.0)$ & $23(7.7)$ & & $22(7.8)$ \\
\hline $51-60 \mathrm{~h}$ & $3(4.2)$ & $9(3.0)$ & & $7(2.5)$ \\
\hline$>60 \mathrm{~h}$ & $1(1.4)$ & $7(2.4)$ & & $6(2.1)$ \\
\hline \multicolumn{5}{|l|}{ Lesion location, $n(\%)$} \\
\hline Anterior cortex & $15(21.1)$ & $71(23.9)$ & $24(27.6)$ & $62(22.1)$ \\
\hline $\mathrm{CR}+\mathrm{BG}+\mathrm{IC}$ & $18(25.3)$ & $92(31.0)$ & $25(28.7)$ & $85(30.2)$ \\
\hline Thalamus & $5(7.0)$ & $35(11.8)$ & $8(9.2)$ & $32(11.4)$ \\
\hline Pons + midbrain & $20(28.2)$ & $42(14$. & $18(20.7)$ & $44(15.7)$ \\
\hline Medulla & $1(1.4)$ & $8(2.7)$ & $1(1.1)$ & $8(2.8)$ \\
\hline Cerebellum & $4(5.6)$ & $17(5.7)$ & $4(4.6)$ & $17(6.0)$ \\
\hline Posterior cortex & $8(11.3)$ & $10.8)$ & $7(8.0)$ & $33(11.7)$ \\
\hline \multicolumn{5}{|l|}{ Laterality, $n(\%)$} \\
\hline Left & $33(46.5)$ & $(44.8)$ & $40(46.0)$ & $126(44.8)$ \\
\hline Right & 2 & $128(43.1)$ & $33(37.9)$ & $119(42.3)$ \\
\hline Bilateral & 14 & $36(12.1)$ & $14(16.1)$ & $36(12.8)$ \\
\hline \multicolumn{5}{|l|}{ White matter change, $n(\%)$} \\
\hline Severe & & $144(48.5)$ & $44(50.6)$ & $141(50.2)$ \\
\hline Mild & $30(42.3)$ & $153(51.5)$ & $43(23.8)$ & $140(49.8)$ \\
\hline \multicolumn{5}{|c|}{ Dysfunction at admission, $n(\%)$} \\
\hline Motor dysfunction & 3) & $165(55.6)$ & $45(51.7)$ & $155(55.2)$ \\
\hline Sensory dysfunction & $7(9.9)$ & $49(16.5)$ & $6(6.9)$ & $50(17.8)^{*}$ \\
\hline Both motor and sensory & $25(35.2)$ & $46(15.5)^{* *}$ & $33(37.9)$ & $38(13.5)^{* *}$ \\
\hline \multicolumn{5}{|l|}{$\mathrm{MCMQ}$, mean $\pm \mathrm{SD}$} \\
\hline Confrontation & $20.4 \pm 2.5$ & $20.1 \pm 2.5$ & $20.4 \pm 2.8$ & $20.1 \pm 2.4$ \\
\hline Avoidance & $14.5 \pm 1.6$ & $14.2 \pm 1.5$ & $14.9 \pm 1.8$ & $14.1 \pm 1.4^{* *}$ \\
\hline Acceptance- & $9.5 \pm 2.0$ & $7.9 \pm 1.8 * *$ & $10.3 \pm 1.7$ & $7.6 \pm 1.6^{* *}$ \\
\hline \multicolumn{5}{|l|}{ SSRS, mean SD } \\
\hline Subjecti sùpport & $23.6 \pm 2.2$ & $23.8 \pm 2.1$ & $23.6 \pm 2.2$ & $23.8 \pm 2.1$ \\
\hline Objective & $9.9 \pm 0.9$ & $9.7 \pm 1.0$ & $9.8 \pm 1.1$ & $9.7 \pm 0.9$ \\
\hline D -gh of soc utilization & $6.0 \pm 1.0$ & $6.0 \pm 1.0$ & $5.8 \pm 0.9$ & $6.1 \pm 1.1 *$ \\
\hline
\end{tabular}

$B 0$ ar gu..olia, $C R$ corona radiata, $I C$ internal capsule, $M C M Q$ Medical Coping Modes Questionnaire, $n$ number, $P S D$ post-stroke depression, $S S R S$ ial Support Rating Scale, $y$ years

$* P \leq 0.05$

$* * P \leq 0.01$

$P<0.05)$ were also predictive factors for PSF. Basal ganglia $(\mathrm{BG})$, corona radiate (CR) or internal capsule (IC) infarction $(P<0.05)$, low degree of social utilization
(SSRS; $P<0.01$ ), confrontation (MCMQ; $P<0.05$ ), and acceptance-resignation (MCMQ; $P<0.01$ ) were all significant risk factors associated with PSF at 3 months 
Table 2 Factors associated with PSF at admission and 3 months later

\begin{tabular}{|c|c|c|c|c|}
\hline \multirow[t]{2}{*}{ Variable } & \multicolumn{2}{|l|}{ Admission } & \multicolumn{2}{|c|}{3 months after stroke } \\
\hline & Present $(n=86)$ & Absent $(n=282)$ & Present $(n=109)$ & Absent $(n=259)$ \\
\hline Age $(y)$, mean \pm SD & $61.8 \pm 9.5$ & $60.5 \pm 10.1$ & $61.7 \pm 9.2$ & $61.5 \pm 9.8$ \\
\hline Female, $n(\%)$ & $22(25.6)$ & $85(30.1)$ & $26(23.9)$ & $81(31.3)$ \\
\hline Education $(\mathrm{y})$, mean $\pm \mathrm{SD}$ & $10.7 \pm 3.7$ & $10.8 \pm 3.4$ & $10.7 \pm 3.4$ & \\
\hline Previous stroke, $n(\%)$ & $40(46.5)$ & $140(49.6)$ & $54(49.5)$ & \\
\hline \multicolumn{5}{|l|}{ Weekly working hours, $n(\%)$} \\
\hline $0 \mathrm{~h}$ & $54(62.8)$ & $162(57.4)$ & $62(56.9)$ & (59.5) \\
\hline $1-20 \mathrm{~h}$ & $0(0.0)$ & $11(3.9)$ & $0(0.0)$ & $4.2)^{*}$ \\
\hline $21-30 \mathrm{~h}$ & $4(4.7)$ & $18(6.4)$ & $5(4.6)$ & $17(6.6)$ \\
\hline $31-40 \mathrm{~h}$ & $14(16.3)$ & $57(20.2)$ & $21(19.3)$ & $50(19.3)$ \\
\hline $41-50 \mathrm{~h}$ & $8(9.3)$ & $20(7.1)$ & & $17(6.6)$ \\
\hline $51-60 \mathrm{~h}$ & $4(4.7)$ & $8(2.8)$ & & $4(15.4)$ \\
\hline More than $60 \mathrm{~h}$ & $2(2.3)$ & $6(2.1)$ & & $6(2.3)$ \\
\hline \multicolumn{5}{|l|}{ Lesion location, $n(\%)$} \\
\hline Anterior cortex & $19(22.1)$ & $67(23.8)$ & $22(20.2)$ & $64(24.7)$ \\
\hline $\mathrm{CR}+\mathrm{BG}+\mathrm{IC}$ & $29(33.7)$ & $81(28.7)$ & $2(38.5)$ & $68(26.3)^{*}$ \\
\hline Thalamus & $9(10.5)$ & $31(11.0)$ & $12(11.0)$ & $28(10.8)$ \\
\hline Pons + midbrain & $19(22.1)$ & $43(15.2$ & $20(18.3)$ & $42(16.2)$ \\
\hline Medulla & $1(1.2)$ & $8(2.8)$ & $4(3.7)$ & $5(1.9)$ \\
\hline Cerebellum & $3(3.5)$ & $18(6.4)$ & $2(1.8)$ & $19(7.3)^{*}$ \\
\hline Posterior cortex & $6(7.0)$ & 12.1) & $7(6.4)$ & $33(12.7)$ \\
\hline \multicolumn{5}{|l|}{ Laterality, $n(\%)$} \\
\hline Left & $38(32.6)$ & $(45.4)$ & $47(43.1)$ & $119(45.9)$ \\
\hline Right & $35(40.7)$ & $117(41.5)$ & $48(44.0)$ & 104(40.2) \\
\hline Bilateral & $13(15 \mu$ & $37(13.1)$ & $14(12.8)$ & $36(13.9)$ \\
\hline \multicolumn{5}{|l|}{ White matter change, $n(\%)$} \\
\hline Severe & & $141(50.0)$ & $56(51.4)$ & $129(49.8)$ \\
\hline Mild & $42(48.8)$ & $141(50.0)$ & $53(48.6)$ & $130(50.2)$ \\
\hline \multicolumn{5}{|c|}{ Dysfunction at admission, $n(\%)$} \\
\hline Motor dysfunction & 8) & $152(53.9)$ & $55(50.5)$ & $145(56.0)$ \\
\hline Sensory dysfunction & $6(7.0)$ & $50(17.7)^{*}$ & $17(15.6)$ & $39(15.1)$ \\
\hline Both motor and sensory d & $29(33.7)$ & $42(14.9)^{* *}$ & $29(26.6)$ & $42(16.2)$ \\
\hline \multicolumn{5}{|c|}{$\mathrm{MCMQ}$ score, mean $\pm \mathrm{SD}$} \\
\hline Confrontation & $20.4 \pm 2.4$ & $20.1 \pm 2.5$ & $20.7 \pm 2.5$ & $20.0 \pm 2.5^{*}$ \\
\hline Avoidance & $14.3 \pm 2.0$ & $14.0 \pm 1.6$ & $14.2 \pm 2.1$ & $14.0 \pm 1.5$ \\
\hline Acceptance-res gna & $9.8 \pm 2.2$ & $7.7 \pm 1.7 * *$ & $8.6 \pm 2.4$ & $8.0 \pm 1.8^{*}$ \\
\hline \multicolumn{2}{|l|}{ SSRS score, } & $23.8 \pm 2.1$ & & $23.7 \pm 2.1$ \\
\hline Objective nort & $9.1 \pm 1.1$ & $9.7 \pm 1.0^{*}$ & $9.8 \pm 0.9$ & $9.7 \pm 1.0$ \\
\hline D -gh of soc utilizatio & $5.8 \pm 0.9$ & $6.1 \pm 1.1^{*}$ & $5.7 \pm 0.8$ & $6.1 \pm 1.1^{* *}$ \\
\hline
\end{tabular}

$B \cup$ ar gundia, $C R$ corona radiata, $I C$ internal capsule, $M C M Q$ Medical Coping Modes Questionnaire, $n=$ number, $P S F$ post-stroke fatigue, SSRS ial Support Rating Scale, $y$ years

$* P \leq 0.05$

$* * P \leq 0.01$

(Table 2). We also found that patients with 1-20 h weekly working time and cerebellum infarction were not susceptible to PSF $(P<0.05$; Table 2$)$.
As presented in tabular form (Table 3), multivariate logistic regression analysis indicated that initial presentation with PSD at admission was related to both motor and 
sensory dysfunction $(P<0.05)$ and acceptance-resignation (MCMQ; $P<0.01$ ), whereas PSD at 3 months was associated with degree of social utilization (SSRS; $P<0.01$ ), avoidance (MCMQ; $P<0.01$ ) and acceptance-resignation (MCMQ; $P<0.01$ ). PSF at admission was also associated with acceptance-resignation (MCMQ; $P<0.01$ ) and low degree of social utilization (SSRS; $P<0.01$ ), whereas it was related to $\mathrm{BG}, \mathrm{CR}$ or IC infarction $(P<0.05)$, the confrontation (MCMQ; $P<0.05$ ) and acceptance-resignation (MCMQ; $P<0.01)$ styles, and low degree of social utilization (SSRS; $P<0.01$ ) (Table 3$)$.

\section{Discussion}

Here as we tracked likely predictors of PSD and PSF in stroke patients to promote early identification and prevention, both conditions changed constantly over time. Fatigue and depression often accompanied occurrence after stroke. Compared with previous studies in which PSF ranged from
36 to $77 \%$ of stroke-afflicted subjects [24], the extent of morbidity documented here represented by was lower, that is, of 71 stroke patients we reviewed. PSF was present in $23.4 \%$ at admission and $29.6 \%$ at 3 months. However, throughout this more than 2-year study, we observed that PSD and PSF changed constantly as time passed.

Dopamine and serotonin are considered esponsible for fatigue in patients with Parkinson's diseas गD, $[257$. With respect to localization of brain damage, 1 ganglia, corona radiate or internal capsul infarctions were the independent factors associated with SF 3 months after stroke occurrence, whereas c rebellum, arction was not susceptible to PSF. Previous, dopanline reward neurons localized in the ventral egm al area were found projecting into the ventr. str $\mathrm{m}$ [26]. Animal experiments have shown that ofuse si otonergic fibers from the brainstem raphe uclo roject to the basal ganglia and the cerebellum [2, In acco 1, , our results suggested that, PSF was relate o d nament of dopaminergic system secondary to stru occurring in strategic areas. Elsewhere,
Table 3 Factors associated with PSD and PSF as analyzed using multiple logistic regression

\begin{tabular}{|c|c|c|c|c|}
\hline Variable & $B$ & SE & $P$ value & $\operatorname{Exp}(B)$ \\
\hline \multicolumn{5}{|l|}{ PSD at admission } \\
\hline Both motor and sen & 0.709 & 0.317 & 0.026 & 2.031 \\
\hline MCMQ score: ac & 0.385 & 0.075 & 0.001 & 1.470 \\
\hline Constant & -4.945 & 0.680 & 0.000 & 0.007 \\
\hline \multicolumn{5}{|l|}{ PSD 3 months la ct } \\
\hline Sensory dysh ion at adjifission: yes & -0.638 & 0.602 & 0.289 & 0.529 \\
\hline Both mo or and su ry dysfunction at admission: yes & 0.537 & 0.387 & 0.165 & 1.711 \\
\hline MCN Q: avoidance, mean \pm SD & 0.404 & 0.118 & 0.001 & 1.498 \\
\hline $\mathrm{MCl} \mathrm{Q}$ : accept ince-resignation, mean $\pm \mathrm{SD}$ & 1.061 & 0.130 & 0.000 & 2.888 \\
\hline SSRS. of social utilization, mean \pm SD & -0.558 & 0.179 & 0.001 & 0.555 \\
\hline Pant & -13.001 & 2.289 & 0.000 & 0.000 \\
\hline \multicolumn{5}{|l|}{$\mathrm{PSF}$ at ; amission } \\
\hline S nnsory dysfunction at admission: yes & -0.611 & 0.511 & 0.232 & 0.543 \\
\hline Both motor and sensory dysfunction at admission: yes & 0.321 & 0.340 & 0.345 & 1.379 \\
\hline MCMQ: acceptance-resignation, mean $\pm \mathrm{SD}$ & 0.624 & 0.087 & 0.000 & 1.866 \\
\hline SSRS: objective support, mean \pm SD & 0.169 & 0.144 & 0.238 & 1.185 \\
\hline SSRS: degree of social utilization, mean \pm SD & -0.401 & 0.154 & 0.009 & 0.670 \\
\hline Constant & -5.849 & 1.988 & 0.003 & 0.003 \\
\hline \multicolumn{5}{|l|}{ PSF 3 month later } \\
\hline Weekly working hours: $1-20 \mathrm{~h}$ & -20.220 & $11,799.472$ & 0.999 & 0.000 \\
\hline Lesion location: $\mathrm{CR}+\mathrm{BG}+\mathrm{IC}$ & 0.634 & 0.260 & 0.015 & 1.885 \\
\hline Lesion location: cerebellum & -1.060 & 0.773 & 0.170 & 0.346 \\
\hline MCMQ score: confrontation, mean \pm SD & 0.118 & 0.051 & 0.021 & 1.125 \\
\hline MCMQ score: acceptance-resignation, mean \pm SD & 0.214 & 0.061 & 0.000 & 1.239 \\
\hline SSRS score: degree of social utilization, mean \pm SD & -0.410 & 0.133 & 0.002 & 0.664 \\
\hline Constant & -2.727 & 1.549 & 0.078 & 0.065 \\
\hline
\end{tabular}

$M C M Q$ Medical Coping Modes Questionnaire, $P S D$ post-stroke depression, $P S F$ post-stroke fatigue, SSRS Social Support Rating Scale 
pharmacological studies yielded a reduction in fatigue following the administration of a dopamine agonist [28]. High, moderate and low concentrations of extracellular dopamine induced euphoric, seeking and aversive states, respectively. Still other findings identified circuit loops involving the cerebral cortex, basal ganglia, thalamus, epithalamus, and midbrain through which dopaminergic activity affected motivation [29]. In that study, lack of energy or motivation, boredom, adynamia and lassitude were the main symptoms of fatigue after stroke. Overall, in our hands, the relationship between PSF and lesion location was not significant during the acute stage indicating that the redistribution of neurotransmitters may take some time. Moreover, there was no evidence that PSD was related to lesion location, despite the correlation between PSF and PSD. Quite possibly though, PSD is an emotional disturbance associated with social stress, premorbid personality or disability caused by stroke. In support, our study confirmed that types of neurologic dysfunction, social support and coping styles were closely associated with PSD. Since neurologic dysfunction was not an independent factor related to PSF, correct cognitive appraisal may be necessary to determine the pathogenesis of PSF.

Although we recorded age, gender, extent of formal education and stroke history as background factors for $\mathrm{t}^{\prime} \mathrm{e}$ patients included here, no significant differences emergea, either at admission or at 3 months later. Although patients with 1-20 h weekly working time were not susec b. to PSF, this feature was not an independent fact $r$ involv development of PSF as judged by multi an analyses. Social support is often found to protect gainst t. effects of stress, with most studies finding ei ner a main eifect or a buffering effect [30]. In our study, : ow degree of social utilization as a cognitive appraisal va. was andependent risk factor associated DSD at 3 months and PSF at both time points after strcke. So, regardless of how much social support yas, esent, patients were routinely encouraged to seek an opportunities during the stroke recovery oeriod. addition, coping styles were associated wit 1 L ability to seek social support. Feifel [20] pointer out that ceptance-resignation indicated that the expre sion of negative affect, lack of focus, and gloomy expectatio bou the future always induced longer illness. Res on as ptance-resignation related to PSD and PSF b at aniosion and at 3 months later revealed that these pati focused on their limited power to influence the course of illness and lost confidence for recovery. High avoidance scores of PSD patients denoted less self-directed life orientation and negative self-perception [20]. Avoidance only associated PSD for individuals with subacute stroke indicated that this style may be effective for managing short-term threats, but for the long-term problem-solving activity was more effective [14]. Higher scores for confrontation by PSF patients indicated the presence of extroversion, negative self-perception, a view of their illness as serious, religiosity, concern about life direction, the situational variables of fearing death, and positive expectations about recovery and the future. So apart from effective cognitive ability, a confrontational coping style was more important for patients with stroke. The results of this study have potentially important nl atic ns for intervention. Possibly, a change in strategh for coping with stroke would reverse HPA-ax dysfunction, thereby avoiding the symptoms of emotiona sturbances and the related pathogenic effects. Fi ially, the esence of a significant relationship between oping ahd cortisol has been noted in other studies ${ }^{21]}$. + s strategies for a new direction to predict nd treat PSD and PSF, and by engendering a gre? willing ss on the part of post-stroke patients to be paticip is in their own recovery, medical practitioners $\ldots$ ht impry ve outcomes.

The m lin lin size of our sample, the re medical center used as a source of patien and the short time period of only 3 months. Becaus thing os the first study that combines the specific attribute measured here, caution dictated applying these limitations as a foundation before engaging in a larger, ger investigation. Further, we excluded patients with se ere neurologic conditions, aphasia, and cognitive mpairment and those who lived alone. The patients who dropped out of the study before 3 months were older and had more severe neurologic dysfunction at admission, suggesting that occurrence of emotional disturbances may have been underestimated.

\section{Conclusion}

Basal ganglia, corona radiate or internal capsule infarction were the independent factors associated with PSF 3 months after stroke occurrence. The appearance of PSD was not related to lesion location. Both motor and sensory dysfunction was independently associated with PSD at admission. A low degree of social utilization was the independent factor associated with PSD and PSF at 3 months after stroke. Acceptance-resignation independently related to PSD and PSF both at admission and 3 months after stroke. Avoidance was the independent factor related to PSD at 3 months, whereas confrontation was the independent factor related to PSF at 3 months after stroke onset.

Acknowledgments We thank our patients for participating this study; Drs. C. Chen, M. Xing for facilitating recruitment of the patients; Dr. C. Zhang for advice; Drs. R. Xue for technical support. This work was financially supported by the National Natural Science Foundation of China (81100887 and 81273287 to Junwei Hao) and the National Key Clinical Specialty Construction Project of China. 


\section{Compliance with ethical standards}

Conflicts of interest The authors report no conflicts of interest. The authors alone are responsible for the content and writing of the paper.

Ethical standard The study was approved by the ethics committees of Tianjin Medical University General Hospital.

Open Access This article is distributed under the terms of the Creative Commons Attribution 4.0 International License (http://crea tivecommons.org/licenses/by/4.0/), which permits unrestricted use, distribution, and reproduction in any medium, provided you give appropriate credit to the original author(s) and the source, provide a link to the Creative Commons license, and indicate if changes were made.

\section{References}

1. WHO publishes definitive atlas on global heart disease and stroke epidemic (2004). Indian J Med Sci 58 (9):405-406

2. Brodtmann A, van de Port IG (2013) Fitness, depression, and poststroke fatigue: worn out or weary? Neurology 81(18):1566-1567. doi:10.1212/WNL.0b013e3182a9f59b

3. Tang WK, Chen YK, Mok V, Chu WC, Ungvari GS, Ahuja AT, Wong KS (2010) Acute basal ganglia infarcts in poststroke fatigue: an MRI study. J Neurol 257(2):178-182. doi:10.1007/ s00415-009-5284-2

4. Li M, Zhang XW, Hou WS, Tang ZY (2015) Impact of depression on incident stroke: a meta-analysis. Int $\mathrm{J}$ Card 1 180:103-110. doi:10.1016/j.ijcard.2014.11.198

5. De Ryck A, Brouns R, Geurden M, Elseviers M, De D $\mathrm{P} P$, Engelborghs S (2014) Risk factors for poststroke d pression: identification of inconsistencies based on a systemat. J Geriatr Psychiatry Neurol 27(3):147-158 coi:10 77 0891988714527514

6. Pompili M, Venturini P, Campi S, Seretti ME, ntebovi F, Lamis DA, Serafini G, Amore M, Girar 1 R (2012) o stroke patients have an increased risk of devel ping suicidal ideation or dying by suicide? An overview of th current 1 terature. CNS Neurosci Ther 18(9):711-721. doi:1 11/i1/155-5949.2012. 00364.x

7. Choi-Kwon S, Han SW, Kwon Ju (2005) Poststroke fatigue: characteristics and related facto s. Cerebrovascular diseases (Basel, Switzerla (2):84 -90. doi:10.1159/000082784

8. Carlsson GE, Molle B1 Consequences of mild stroke in $\mathrm{p}$ sons 75 years-a 1-year follow-up. Cerebrovasc Dis $16 \quad$ :383-38 o 10 : $10.1159 / 000072561$

9. Astrom M, Ado on R, Asplund K (1993) Major depression in stroke patients. $\quad 3$-year longitudinal study. Stroke 24(7):976-982

10. Moh $\eta$ Valor R (1995) Sleep apnea in patients with hemisph stro.e. Arch Phys Med Rehabil 76(1):71-76

11. 0. EL, gmayr B, Asplund K (2002) Poststroke fatigue: a 2-ye follow-up study of stroke patients in Sweden. Stroke 5):1 $21-1333$

12. Fo án S, Lazarus RS, Gruen RJ, DeLongis A (1986) Appraisal, coping, health status, and psychological symptoms. J Pers Soc Psychol 50(3):571-579

13. Moos R, Tsu V (1977) The Crisis of physical illness: an overview. In: Moos R (ed) Coping with physical illness. Springer, US, pp 3-21. doi:10.1007/978-1-4615-9089-7_1
14. Donnellan C, Hevey D, Hickey A, O'Neill D (2006) Defining and quantifying coping strategies after stroke: a review. J Neurol Neurosurg Psychiatry 77(11):1208-1218. doi:10.1136/jnnp.2005. 085670

15. Shek DT (1990) Reliability and factorial structure of the Chinese version of the Beck depression inventory. J Clin Psychol 46(1):35-43

16. Schwartz JE, Jandorf L, Krupp LB (1993) The easurement of fatigue: a new instrument. J Psychosom Res 2/(7):753-762

17. Chen SX, Yu FM (2008) Syndrome different $n$ und t atment of post-stroke fatigue. J Pract Tradit Chin Int $N_{1}$ 22:/1-19

18. Folstein MF, Folstein SE, McHugh PR (1975) dini-mental state". A practical method for gra the co nitive state of patients for the clinician. J Psych ...r. Re ?(3)/189-198

19. Xiao SY (1994) The theoretica basis and res arch applications of "Social Support Rating Scale J Clin P ychiatry 4(2):98-100

20. Feifel H, Strack S, Na y I 1987) Coping strategies and associated features of $\mathrm{h}$ cally $\ldots$ patients. Psychosom Med 49(6):616-625

21. Wang XD, Wan health. Chinese Men . Jealth J (Chin). 250-256. doi:10.1111/j. 1365-2230. $2^{\circ 1} 03831$.

22. Choi-Kw in S, an SW, Kwon SU, Kang DW, Choi JM, Kim JS (2006) $F$ atment in poststroke depression, emotional incontinence $n d$ anger proneness: a double-blind, placebocol olled stua . Stroke 37(1):156-161. doi:10.1161/01.STR. 000 1) $3663 . \mathrm{e} 2$

23. Choi K.won S, Han K, Choi S, Suh M, Kim YJ, Song H, Cho KH, Nah IW, Kwon SU, Kang DW, Kim JS (2012) Poststroke depression and emotional incontinence: factors related to acute and subacute stages. Neurology 78(15):1130-1137. doi:10.1212/ WNL.0b013e31824f8090

Chen YK, Qu JF, Xiao WM, Li WY, Weng HY, Li W, Liu YL, Luo GP, Fang XW, Ungvari GS, Xiang YT (2015) Poststroke fatigue: risk factors and its effect on functional status and healthrelated quality of life. Int J Stroke 10(4):506-512. doi:10.1111/ ijs. 12409

25. Abudi S, Bar-Tal Y, Ziv L, Fish M (1997) Parkinson's disease symptoms-patients' perceptions. J Adv Nurs 25(1):54-59

26. Ikemoto $S$ (2007) Dopamine reward circuitry: two projection systems from the ventral midbrain to the nucleus accumbensolfactory tubercle complex. Brain Res Rev 56(1):27-78. doi:10. 1016/j.brainresrev.2007.05.004

27. Bishop GA, Ho RH (1985) The distribution and origin of serotonin immunoreactivity in the rat cerebellum. Brain Res 331(2):195-207

28. Richard PO, Fleshner NE, Bhatt JR, Hersey KM, Chahin R, Alibhai SM (2014) Phase II, randomised, double-blind, placebocontrolled trial of methylphenidate for reduction of fatigue levels in patients with prostate cancer receiving LHRH-agonist therapy. BJU Int. doi:10.1111/bju.12755

29. Ikemoto S, Yang C, Tan A (2015) Basal ganglia circuit loops, dopamine and motivation: a review and enquiry. Behav Brain Res 290:17-31. doi:10.1016/j.bbr.2015.04.018

30. Lakey B, Orehek E (2011) Relational regulation theory: a new approach to explain the link between perceived social support and mental health. Psychol Rev 118(3):482-495. doi:10.1037/ a0023477

31. Hori H, Teraishi T, Ota M, Hattori K, Matsuo J, Kinoshita Y, Ishida I, Nagashima A, Koga N, Higuchi T, Kunugi H (2014) Psychological coping in depressed outpatients: association with cortisol response to the combined dexamethasone/CRH test. J Affect Disord 152-154:441-447. doi:10.1016/j.jad.2013.10.013 